\title{
A dynamic clinical pathway for the treatment of patients with early breast cancer is a tool for better cancer care: implementation and prospective analysis between 2002-2010
}

Peter A van Dam, Gerda Verheyden ${ }^{1}$, Alessa Sugihara², Xuan B Trinh ${ }^{1}$, Herman Van Der Mussele ${ }^{1}$, Hilde Wuyts ${ }^{1}$, Luc Verkinderen ${ }^{1}$, Jan Hauspy ${ }^{1}$, Peter Vermeulen ${ }^{1}$ and Luc Dirix ${ }^{1}$

\begin{abstract}
Background: Due to increasing the complexity of breast cancer treatment it is of paramount importance to develop structured care in order to avoid a chaotic and non-consistent management of patients. Clinical pathways, a result of the adaptation of the documents used in industrial quality management namely the Standard Operating Procedures, can be used to improve efficiency and quality of care. They also aim to re-centre the focus on the patient's overall journey, rather than the contribution of each specialty or caring function independently.

Methods: The effect of the implementation and prospective systematic evaluation of a clinical care pathway for the management of patients with early breast cancer in a single breast unit is evaluated over a long time interval (between 2002 and 2010). Annual analysis of predefined clinical outcome measures, service indicators, team indicators, process indicators and financial indicators was performed. Pathway quality control meetings were organized at least once a year. Systematic feedback was given to the team members, and if necessary the pathway was adapted according to evidence based literature data and in house pathway related data in order to improve quality.

Results: The annual number of patients included in the pathway (289 vs. 390, $P<0.01$ ), proportion of patients with Tis-T1 tumors ( $42 \%$ vs. $58 \%, P<0.01$ ), negative lymph nodes ( $44 \%$ vs. $58 \%, P<0.01)$ and no metastases at diagnosis (91.5\% vs. 95.9\%) has risen significantly between 2002 and 2010. Evolution of mandatory quality indicators defined by EUSOMA shows a significant improvement of quality of cancer care. Particularly, the proportion of patients having anti-hormonal therapy ( $84.8 \%$ vs. $97.4 \%, P=0.002)$ and adjuvant chemotherapy according to the guidelines (72\% vs. $95.6 \%, P=0.028)$ increased dramatically. Patient satisfaction improved significantly $(P<0.05)$. Progression free 4-year survival was significantly higher for all patients, for T1 tumors only and for T2-T4 tumors only, treated between 2006 to 2008 compared to between 1999 to 2002 and 2003 to $2005(P=0.006, P=0.05, P=0.06$, respectively). Overall 4-year survival of the entire population treated between 2006 and 2008 was significantly better $(P=0.05)$.

Conclusions: Although the patient characteristics changed over the years due to better screening, this clinical pathway and regular audit of quality indicators for the treatment of patients with operable breast cancer proved to be important tools to improve the quality of care, patient satisfaction and outcome.
\end{abstract}

Keywords: Breast cancer, Chemotherapy, Clinical pathway, Quality control, Radiotherapy, Surgery

\footnotetext{
* Correspondence: peter.vandam@telenet.be

'Breast Unit, Department of Gynecology, Sint-Augustinus Hospital,

Oosterveldlaan 24, Wilrijk, Belgium

Full list of author information is available at the end of the article
}

\section{Biomed Central}

(C) 2013 van Dam et al.; licensee BioMed Central Ltd. This is an Open Access article distributed under the terms of the Creative Commons Attribution License (http://creativecommons.org/licenses/by/2.0), which permits unrestricted use, distribution, and reproduction in any medium, provided the original work is properly cited. 


\section{Background}

Several publications have suggested that the quality of health care received by patients in the Western world does not always match the ideal care. In a survey of 30 health conditions ranging from osteoarthritis to breast cancer, McGlynn et al. observed that on average Americans received about half (54.9\%) of the recommended medical care processes [1]. It has also been reported that in Europe there are wide differences in treatment offered to patients with breast cancer in terms of mastectomy and radiotherapy rates and the use of adjuvant chemotherapy and hormone therapy, which results in considerable survival differences [2,3]. These observations highlight a gap between optimal and actual care, that is, between what evidence has identified as recommended care and what patients actually receive [4]. They show that there is a worldwide need for tools to improve adherence to guidelines in the daily clinical practice.

High-quality services are essential to optimize treatment results of women with breast cancer. They can be achieved by accurate training, specialization, volume levels and a multidisciplinary approach, involving many different subspecialists, nursing staff and supporting staff members [5]. Due to the increasing complexity of breast cancer treatment and the teams involved, it is of paramount importance to develop structured care in order to avoid a chaotic and non-consistent management of patients.

A clinical care pathway is a methodology for the mutual decision making and organization of care for a well-defined group of patients during a well-defined period of time [6]. The aim of a clinical care pathway is to improve quality of care, reduce risks of unintended effects and death, increase patient satisfaction and improve efficiency of resource usage [7]. Clinical care pathways are developed by multi-professional teams, composed by different types of physicians, nurses, social workers and administrators, who manage disease processes and are responsible for patient care [8]. Continuous evaluation and follow-up of quality indicators should guarantee the effectiveness of a clinical care pathway. Five domains for evaluation can be distinguished: clinical outcome, service indicators, team indicators, process indicators and financial indicators [9]. A review on quality of cancer care, guidelines and clinical pathways demonstrated improvements in compliance to guidelines and evidence based medicine, and reduction of length of hospital stay, complication rates and financial costs [10]. The present paper describes the effects of the development, implementation and prospective systematic evaluation and adaptation of a clinical care pathway for the management of patients with operable breast cancer in a single breast unit over a long time interval (between 2002 and 2010).

\section{Methods}

\section{The hospital setting}

The Sint-Augustinus Hospital is a non-academic teaching hospital in Belgium. The Oncology Unit of the hospital is integrated in a local cancer network (Iridium Network), collaborates closely with Leuven University, Belgium, and is the second largest of Flanders. Every year up to 400 new breast cancer patients receive surgical treatment in this unit. Most patients are referred by local GP's or the regional screening units.

Given that the multidisciplinary oncology team consisted of more than 40 physicians of different specialties, 50 members of the nursing staff, and 10 social workers and psychologists, a clinical pathway for the diagnosis, surgical treatment and decision making of adjuvant treatment in patients with operable breast cancer was developed in 2002 in an attempt to provide more uniform cancer care. Patients with a suspicious breast lesion obtain an appointment in the oncology outpatient clinic within two days, and by triple assessment a rapid diagnosis is achieved within five days. The postoperative multidisciplinary breast team meeting (held twice a week) outlines an individualized postoperative treatment plan based on the local cancer network guidelines (adaptation of the Sankt Gallen guidelines) [11-15]. Further treatment is carried out according to this plan if the patient agrees. Multidisciplinary follow-up is organized every 3 months, the first 3 years and biannually on the fourth and fifth year.

In 2005 a breast nurse was introduced to facilitate the patient's journey through the multidisciplinary track and to be a gate-keeper of the clinical pathway. From January 2006 onwards immunohistochemical assessment of estrogen receptor, progesterone receptor and c-erbB-2 was standardized using FDA approved FARM DX and Herceptest Dako immunohistochemistry (Dako, Carpinteria, CA, USA) [16,17]. In January 2007 the Breast Clinic of the Sint-Augustinus Hospital was formally opened. It was organized according to European Society of Breast Cancer Specialists (EUSOMA) guidelines [18]. A breast multidisciplinary core team consisting of full-time breast surgeons, medical oncologists, radiotherapists, breast radiologists, histopathologists, breast care nurses, database manager, clinical geneticist, psychologists and reconstructive surgeons, was established. All patients with a new breast cancer diagnosis have a preoperative visit with a member of the core team. In addition a preoperative multidisciplinary meeting was introduced. Adaptations to the clinical pathway were made in 2008 in order to make it compatible with Flemish requirements for breast clinics. In 2008 the breast clinic of the Sint-Augustinus Hospital obtained its formal accreditation by the Flemish Government and EUSOMA [19]. Two new breast nurses were incorporated in the team in 2009, as our original breast nurse moved up in the administrative staff of the 
hospital. In 2010 our unit was the first unit in Belgium to receive a European Cancer Care Certificate, a quality label for breast cancer care. The pathology laboratory received an ISO2000 accreditation in 2010.

\section{Prospective data collection}

As the hospital management wishes to guarantee high quality care by improving processes, since 2002, performance measurements have been documented systematically by care providers using an order communication, planning and result reporting system [20]. The nursing process is integrated in the clinical pathway "operable breast cancer". The order communication system "patient care system" (PCS) is an IBM (New York, USA) mainframe based application working under Customer Information Control System (CICS) and using a Data Language One (DL/I) database. It has been completely adapted to the hospital requirements, by its own IT staff. It is developed as a level three electronic patient record as described by Brennan [21]. It contains clinical ward based applications including order communications and results reporting, multidisciplinary clinical pathways, electronic prescribing and drug administration.

The documentation process was improved by setting up a structured organization of data collection into the hospital informatics system, based on clear procedures discussed with care providers to make sure the data collection was achievable. As input of the many process parameters was very time consuming, it was decided to collect data and monitor them for the first half of every calendar year, so that in the second half of the year other care pathways could be assessed. Patient satisfaction was measured prospectively in 60 consecutive patients prior to discharge at the beginning of every year. A previously validated questionnaire developed by the Belgian-Dutch Clinical Pathway Network (BDCPN) on 19 different aspects of organization of care was used. It is based on a larger questionnaire developed by Chou et al. [22], and adapted and translated from English to Dutch. Questions were scored from 1 to 4 (1: dissatisfied; 2: more or less dissatisfied; 3: more or less satisfied; 4: satisfied). The responsibility for gathering correct data was identified and a structured follow-up was organized. Feedback and discussion of data and information of the responsible team was organized annually.

\section{Clinical pathway}

The clinical pathway "operable breast cancer" was developed by the methodology described by the BDCPN [23]. The multidisciplinary team formulated the outcome parameters, critical indicators and key activities to deal with the patient's condition. The clinical pathway is described by a time task matrix and integrated into the IT system PCS. The latest version of our clinical pathway operable breast cancer is attached to this manuscript (Additional file 1). Annual analysis of predefined clinical outcome measures, service indicators, team indicators, process indicators and financial indicators was performed. Pathway quality control meetings were organized at least once a year with the members of the core team, other medical providers and the hospital administrators. Systematic feedback was given to the team members, and if necessary the pathway was adapted according to evidence based literature data and in-house pathway related data in order to improve quality. Survival data were collected systematically for patients included in the in-house electronic patient records. If the patients were not followed in our hospital, their general practitioners were annually contacted to provide survival related information.

\section{Statistical analysis}

The SPSS6 package was used for the statistical analysis of the data.

\section{Results}

Characteristics of the patients treated between 2002 and 2010 are given in Table 1. As can be seen the number of patients included in the pathway and proportion of patients with small tumors, negative lymph nodes and no metastases at diagnosis has risen significantly over the years. Histological subtypes have remained the same, but the proportion of patients with hormone receptor negative tumors dropped significantly after the introduction of PharmDX immunohistochemical determination of hormone receptors in 2006.

Table 2 shows the major clinical indicators between 2002 and 2010, indicating that the average length of hospital stay nearly halved and the proportion of breast conserving surgery, preoperative guide-wire localization for impalpable lesions and use of sentinel node biopsy increased significantly. Median duration of hospital stay was reduced for patients treated by mastectomy or breast conserving surgery from 9 and 4 days in 2002 to 7 and 2.5 days in 2010, respectively $(P<0.01)$. The percentage of second surgery (to achieve free margins by additional local resection or mastectomy, or to perform a complete axillary dissection after a sentinel node biopsy which was negative during preoperative assessment but proved to contain metastatic cells at final pathological analysis) dropped from 25 to $10 \%(P<0.01)$. Sentinel node biopsy was introduced between 2005 and 2006, and its use remained stable over the years. Staging examinations have increasingly been performed preoperatively over the years. In 2009, when we had to incorporate two new breast nurses, a temporary drop of incompletely met discharge criteria was noted, which was corrected in 2010 after these nurses were further trained. "Completeness of discharge criteria" and "normal wound at discharge" were 
Table 1 Patient characteristics between 2002 and 2010 in the clinical pathway "operable breast cancer"

\begin{tabular}{lccccccccc}
\hline Indicator & $\mathbf{2 0 0 2}$ & $\mathbf{2 0 0 3}$ & $\mathbf{2 0 0 4}$ & $\mathbf{2 0 0 5}$ & $\mathbf{2 0 0 6}$ & $\mathbf{2 0 0 7}$ & $\mathbf{2 0 0 8}$ & $\mathbf{2 0 0 9}$ & $\mathbf{2 0 1 0}$ \\
\hline Number of patients in pathway & 140 & 130 & 130 & 108 & 164 & 176 & 146 & 169 & $183^{*}$ \\
Percentage pTis-pT1 (\%) & 42 & 39 & 60 & 55 & 55 & 58 & 60 & 55 & $58^{*}$ \\
Percentage pNO (\%) & 44 & 52 & 46 & 48 & 51 & 58 & 57 & 52 & $58^{*}$ \\
Percentage M1 at diagnosis & 8.5 & 8.4 & 5.7 & 10 & 4.5 & 7.7 & 5.5 & 2.6 & $4.1^{*}$ \\
Percentage IDC (\%) & 78 & 76 & 84 & 84 & 77 & 79 & 81 & 79 & $81^{*}$ \\
Percentage ER negative (\%) & 26 & 21 & 34 & 31 & 19 & 20 & 23 & 18 & $18^{*}$ \\
\hline
\end{tabular}

*: $P<0.05$ comparing 2002 vs. 2010.

IDC: invasive ductal carcinoma, ER: estrogen receptor.

Data were collected in the first semester of each year.

significantly better in the second half (2007 to 2010) of the evaluation period compared to the first half (2003 to 2005).

Table 3 shows clinical indicators on postoperative day 1 which remain stable over the years. Of the EUSOMA indicators, ten are currently being monitored for the purpose of Cancer Care Certification by the use of the EUSOMA multi-institutional European Database. The time trend in results of these ten indicators in our unit is shown in Table 4. It can be seen that most of these indicators were significantly better in 2010 compared to 2003. EUSOMA criteria were met for all indicators in 2010. In Table 5 patient satisfaction is outlined. This clearly shows that patient satisfaction improved progressively over the years and was maximal in early 2009. There was a significantly higher patient satisfaction for 13 out of 19 parameters $(P<0.05)$ measured in 2009 compared to 2003. The general level of patient satisfaction was very high. A slight drop in patient satisfaction was noted when the breast nurses changed at the end of 2009. Special teaching sessions were organized to improve this, and were clearly effective (Table 5). Progression free 4-year survival was significantly higher for all patients, for T1 tumors only and for T2-T4 tumors only, treated between 2006 and 2008 compared to between 1999 and 2002 and
2003 and $2005(P=0.006, P=0.05, P=0.06$, respectively) (Figure 1). Overall 4-year survival of the entire population treated between 2006 and 2008 was significantly better $(P=0.05)$.

\section{Discussion}

The clinical pathway concept appeared for the first time at the New England Medical Center (Boston, USA) in 1985 inspired by Zander and Bower [7]. Clinical pathways were a result of the adaptation of the documents used in industrial quality management, the Standard Operating Procedures, whose goals are to improve efficiency in the use of resources and to finish work in a set time. They also aim to re-centre the focus on the patient's overall journey, rather than the contribution of each specialty or caring function independently. The difference between a pathway and a guideline is that a guideline defines the numerous acceptable treatment options that fall within the standard of care, whereas a pathway drives physicians toward a single treatment with predictable toxicities and minimal cost. Although the majority of patients are treated according to the pathway, it is possible for the team not to comply with the pathway for a particular case, but the reasons to do this have to be clearly documented.

Table 2 Process indicators in the period 2002 to 2010 in the clinical pathway "operable breast cancer"

\begin{tabular}{|c|c|c|c|c|c|c|c|c|c|}
\hline Indicator & 2002 & 2003 & 2004 & 2005 & 2006 & 2007 & 2008 & 2009 & 2010 \\
\hline Number of patients in pathway & 140 & 130 & 130 & 108 & 164 & 176 & 146 & 169 & $183 *$ \\
\hline Total days of hospital stay (d) & 991 & 913 & 980 & 651 & 936 & 872 & 730 & 848 & 745 \\
\hline Average hospital stay/patient (d) & 7.0 & 7.0 & 7.5 & 6.0 & 5.7 & 4.9 & 5.0 & 5.0 & $4.1^{*}$ \\
\hline Breast conserving surgery $(\mathrm{N}, \%)$ & $60(43)$ & $58(45)$ & $58(45)$ & $56(52)$ & $86(53)$ & 104(59) & $82(56)$ & $96(57)$ & $106(58)^{*}$ \\
\hline Preoperative guide wire (N, \%) & $20(14)$ & $26(20)$ & $27(21)$ & $23(21)$ & $36(22)$ & 28(16) & $28(20)$ & $35(21)$ & $50(27)^{*}$ \\
\hline Sentinel node biopsy (N, \%) & $0(0)$ & $7(5)$ & $29(22)$ & $48(44)$ & $74(45)$ & $82(46)$ & $58(39)$ & $64(38)$ & $90(49)^{*}$ \\
\hline Preop staging tests $(\mathrm{N}, \%)$ & $74(53)$ & $61(47)$ & $56(43)$ & $16(15)$ & $38(23)$ & $46(26)$ & $19(13)$ & $70(30)$ & $22(12)^{*}$ \\
\hline All discharge criteria not Satisfactory (N, \%) & NR & $16(12)$ & $19(15)$ & $16(15)$ & $18(11)$ & $14(8)$ & $7(5)$ & $30(18)$ & $16(9)$ \\
\hline Wound not satisfactory at Planned discharge (N, \%) & NR & $4(3)$ & $12(9)$ & $10(9)$ & $3(2)$ & $3(2)$ & $0(0)$ & $5(3)$ & $6(3)$ \\
\hline
\end{tabular}

$\mathrm{N}$ : number of patients, d: days; \%: percentage; NR: not recorded.

*: $P<0.05$ comparing 2002 vs. 2010.

Data were collected in the first semester of each year. 
Table 3 Clinical indicators on the first postoperative day in the period 2004 to 2010 in the clinical pathway "operable breast cancer"

\begin{tabular}{lcccccc}
\hline Indicator & $\mathbf{2 0 0 4}$ & $\mathbf{2 0 0 7}$ & $\mathbf{2 0 0 8}$ & $\mathbf{2 0 0 9}$ & $\mathbf{2 0 1 0}$ & $\boldsymbol{P}$ value (2004-2010) \\
\hline Drainage first 24 hours $(\mathrm{mL})$ & 28.6 & 25.0 & 26.4 & 27.9 & 25.1 & NS \\
VAS score $>3(\mathrm{~N})$ & $38(29)$ & $19(10)$ & 19 & 65 & 49 & NS \\
Postoperative vomiting first 24 hours (N) & $2(2)$ & 2 & 3 & 9 & 11 & NS \\
Postoperative fever $\left(37.9^{\circ} \mathrm{C}\right)(\mathrm{N})$ & $0(0)$ & 1 & 3 & 0 & 0 & NS \\
Norton score (average day 1) & 20.0 & 19.9 & 19.9 & 19.8 & 19.9 & NS \\
\hline
\end{tabular}

NS: not significant, $\mathrm{N}$ : number of patients.

Data were collected in the first semester of each year.

Literature data on the use of clinical pathways for breast cancer care are limited to a few small studies. Kasahara and Tawaraya, in Japan, used five clinical pathways for the treatment of breast cancer patients [24]. They concluded that the clinical pathway brought standardization in their institution. The clinical pathway proved to be useful in coping with alternative operating methods, increased the use of adjuvant chemotherapy and increased the number of patients treated as outpatients. Santoso et al. showed, in a prospective analysis of a mastectomy clinical pathway over a seven month period in Singapore, that implementation of the clinical pathway improved consistency in patient treatment, the quality of patient outcome, and reduced costs of care and length of stay [25]. Hwang et al. found, in a retrospective analysis of 29 patients undergoing a transverse rectus abdominis breast reconstruction included in a clinical pathway compared to 40 similar non-pathway patients, that implementation of the reconstruction clinical pathway resulted in significant declines in length of stay and

Table 4 Evolution of quality indicators as formulated by EUSOMA prospectively evaluated between 2003 and 2010 (data for first semester)

\begin{tabular}{|c|c|c|c|c|c|c|}
\hline \multicolumn{2}{|l|}{ Outcome measure } & \multicolumn{2}{|l|}{2003} & \multicolumn{2}{|l|}{2010} & \multirow[t]{2}{*}{$P$ value } \\
\hline EUSOMA & & & & & & \\
\hline Minimum standard & Target & $\mathbf{N}$ & $\%$ & $\mathbf{N}$ & $\%$ & \\
\hline Positive preoperative cyto/histological diagnosis & & $77 / 130$ & $59.7 \%$ & $161 / 183$ & $88.4 \%$ & 0.0001 \\
\hline $80 \%$ & $90 \%$ & & & & & \\
\hline Operated invasive carcinoma for which hist. type, grading ER/PR, s & size were recorded & $106 / 112$ & $94.6 \%$ & $178 / 181$ & $98.3 \%$ & 0.1467 \\
\hline $90 \%$ & $95 \%$ & & & & & \\
\hline Operated non invasive carcinoma for which size, histological type & ding are recorded & $5 / 7$ & $71 \%$ & $28 / 29$ & $96.5 \%$ & 0.4966 \\
\hline $95 \%$ & $98 \%$ & & & & & \\
\hline More than 9 lymph nodes removed when ALD performed (exclud & oling) & $97 / 112$ & $85.6 \%$ & $67 / 70$ & $95.7 \%$ & 0.0434 \\
\hline $95 \%$ & $98 \%$ & & & & & \\
\hline Postoperative radiotherapy in $\mathrm{MO}$ invasive $\mathrm{CA}$ with $\mathrm{BCT}$ & & $50 / 51$ & $98 \%$ & $105 / 108$ & $97.2 \%$ & 0.7588 \\
\hline $90 \%$ & $95 \%$ & & & & & \\
\hline BCT in invasive carcinoma with total size up to $30 \mathrm{~mm}$ (including & mponent) & $49 / 79$ & $62 \%$ & $86 / 104$ & $82.6 \%$ & 0.0016 \\
\hline $70 \%$ & $80 \%$ & & & & & \\
\hline BCT in carcinoma in situ up to $20 \mathrm{~mm}$ & & $3 / 7$ & $43.8 \%$ & $11 / 14$ & 78.6 & 0.0016 \\
\hline $70 \%$ & $80 \%$ & & & & & \\
\hline Ductal carcinoma in situ without axillary dissection & & $6 / 7$ & $85.7 \%$ & $22 / 23$ & $95.6 \%$ & 0.3560 \\
\hline $80 \%$ & $90 \%$ & & & & & \\
\hline Hormonotherapy in endocrine sensitive invasive carcinoma & & $89 / 105$ & $84.8 \%$ & $151 / 155$ & $97.4 \%$ & 0.0002 \\
\hline $80 \%$ & $90 \%$ & & & & & \\
\hline Adjuvant chemotherapy in ER- (PT1c+ or $\mathrm{N}+$ ) invasive Carcinoma & & $18 / 25$ & $72 \%$ & $22 / 23$ & $95.6 \%$ & 0.0280 \\
\hline $80 \%$ & $90 \%$ & & & & & \\
\hline
\end{tabular}

$\mathrm{N}$ : number of patients; \%: percentage of successful outcome measure/total number of cases; ER: estrogen receptor; PR: progesterone receptor; ALD: axillary lymph node dissection; BCT: breast conserving therapy; DCIS: ductal carcinoma in situ; significance level calculated with two-tailed $\chi^{2}$ test without Yates correction. 
Table 5 Patient satisfaction in the clinical pathway "operable breast cancer" (systematically scored prospectively on 60 consecutive patients in the beginning of the year between 2003 and 2010)

Satisfaction indicator Year

How satisfied were you about:

\section{3}

2004

2005

2006

2008 Year

Information on how to prepare your stay in the hospital

$\begin{array}{lllll}79 & 72 & 77 & 98 & 98\end{array}$

Information on the course of your stay (moment of admission until discharge)

$\begin{array}{lllll}85 & 85 & 87 & 93 & 97\end{array}$

Information on how to prepare for a test or a treatment

$\begin{array}{llllll}85 & 87 & 90 & 98 & 98 & 100\end{array}$

Explanation of the provided care before and during it was carried out

$$
\begin{array}{llll}
91 & 92 & 90 & 95
\end{array}
$$

Information on your disease

$$
87
$$

90

98

98

97

98

Information which you received concerning the possible assistance after your discharge

$$
\begin{array}{lllll}
77 & 90 & 97 & 95 & 98
\end{array}
$$

95

95

90

$87 \quad 93$

$93 \quad 95$

75

Smooth completion of your admission to the hospital

$\begin{array}{lllll}92 & 95 & 96 & 98 & 98\end{array}$

tions and general organization of care

Consecution of investigative tests, interventions and general organization of care

$\begin{array}{llllll}92 & 92 & 93 & 98 & 100 & 100\end{array}$

92

Significance level ( $P$ value)

009

2010

2003-2009

2009-2010

100

85

0.001

0.01

Waiting times during your hospital stay

$\begin{array}{llllll}75 & 100 & 97 & 85 & 90 & 97\end{array}$

97

82

NS

Complying of doctors and nurses with appointment during your stay
90
90
93
93
95
100

88

0.03

0.03

Hospital staff caring about a person, in a sense that you were not just a part of their job
70
95
97
97
100

100

98

$>0.001$

NS

Preparation you received to care for yourself after the moment of discharge
80
90
97
100
92
100

97

$>0.001$

NS

Degree in which you felt ready to leave the hospital at the moment of discharge
90

$$
95
$$
97
97
100
100

97

0.03

NS

Kindness of the care providers

$$
90 \quad 97
$$

$$
100
$$

100

100

98

98

NS

NS

Similarity of implementation of returning care

$$
88 \quad 90
$$

95

97

98

98

100

NS

NS

Teamwork among doctors, nurses, physiotherapists and other hospital staff
95
97
98
100

98

100

100

NS

NS

Guarantees of your privacy and dignity during your stay

$\begin{array}{lllllllll}90 & 92 & 97 & 97 & 100 & 100 & 100 & 0.03 & \text { NS }\end{array}$

Initiative to keep your family well informed on your conditions

$\begin{array}{llllll}66 & 92 & 92 & 98 & 100 & 100\end{array}$

100

$>0.001$

NS 


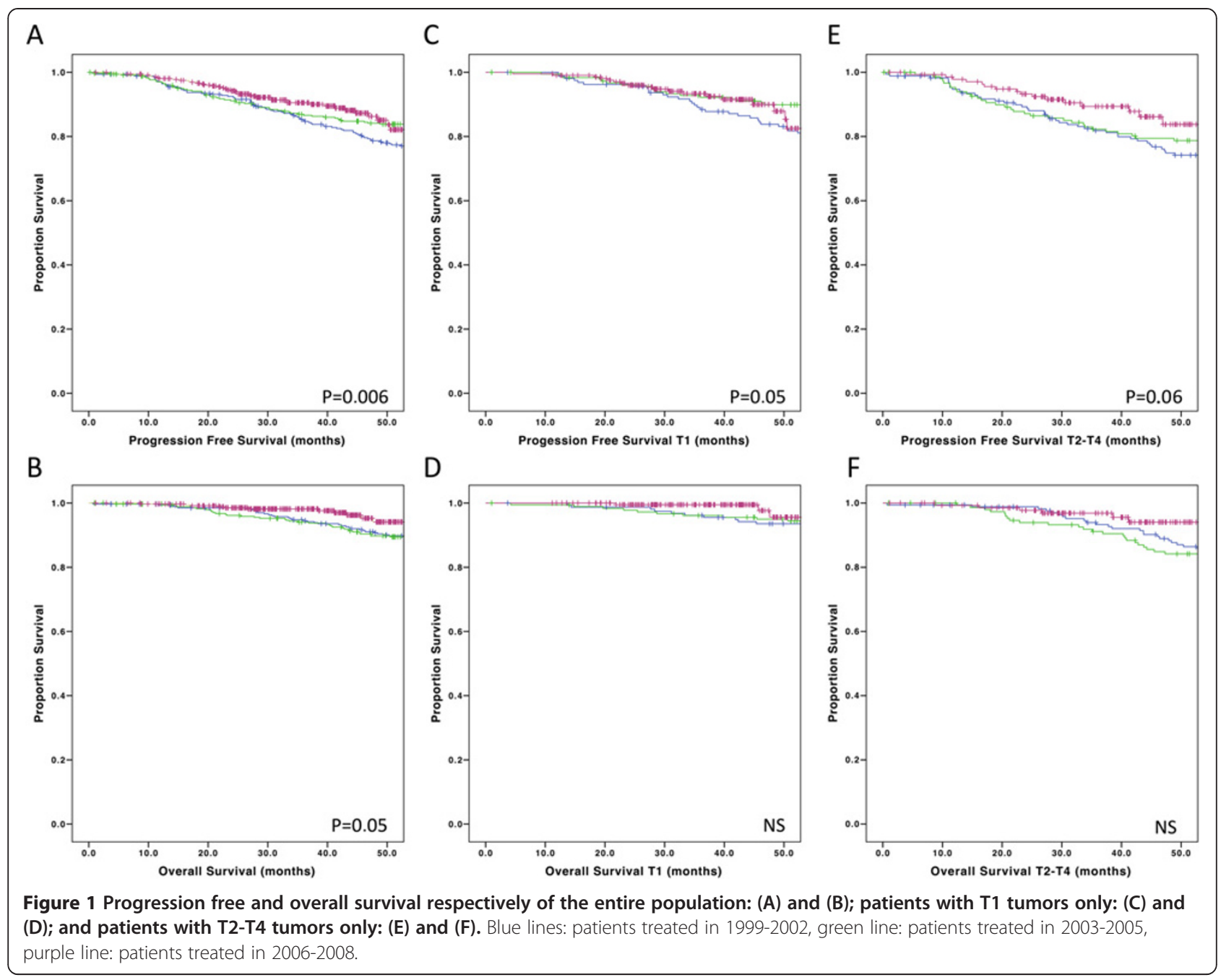

hospital costs but had no effect on complication rates [26]. Lee et al. showed that a clinical pathway for deep inferior epigastric perforans flap breast reconstruction reduced operating time and costs, and improved quality measures and staff satisfaction [27]. Ryhanen et al. demonstrated that clinical pathways can be used to increase patients' knowledge of their disease and empowerment [28].

Goebel et al. concluded that clinical pathways can prevent malpractice lawsuits in breast cancer and radiation therapy [29]. In their retrospective analysis from the LexisNexis and Westlaw legal databases, they found that if physicians had adhered to clinical pathways, 49 out of 72 law-suits decided in favor of the plaintiff patient could have been avoided. In a recent project in Michigan it was suggested that the use of a breast cancer pathway reduces errors and costs, and increases efficiency [30]. These authors also found that patient satisfaction had increased since pathways were implemented. Particularly in an era of personalized medicine, clinical pathways are a tool to establish a model of care that drives oncologists towards evidence based medicine with measurable outcomes in order to achieve high quality patient outcomes at an affordable cost.

The present paper is the first to describe a prospective long-term analysis of the use of a clinical pathway to optimize management of large cohorts of patients with operable breast cancer. It clearly shows that a pathway can be a useful tool to assure uniform care and to improve adherence to guidelines. Continuous registration of quality indicators, treatment related data and regular feedback of the outcomes to the breast team improved quality of care significantly. Evaluation of the pathway data allows for corrective measures to improve care. When, for example, we noted more postoperative pain on day two in 2008 or more vomiting in 2010, a meeting was organized with the anesthetists, in order to improve the pathway. These corrective measures were effective and reduced these symptoms adequately. It should be mentioned that the exact "cocktail" of medication used for general anesthesia is not part of the pathway and depends on the preference 
of the anesthetist. A striking reduction in patient satisfaction was noted in 2009 when our original breast nurse moved up in the organization and was replaced by two full time breast nurses due to the increased workload. Particularly information for patients on how to prepare for their stay in the hospital, the waiting times during the hospital stay and compliance of doctors and nurses with appointments during the patients hospital stay was significantly lower. Special sessions were held with the breast nurses individually and with the entire core team, to bring this back to normal.

A recent Taiwanese study shows that when breast cancer patients are diagnosed and treated in complete accordance with widely accepted standards of care, they survive longer and have better outcomes [31]. This prospective study followed 1,378 newly diagnosed breast cancer patients from 1995 to 2001 in a single cancer hospital, tracking 10 indicators of care quality and assessing the progression of disease up to June 2007. Adherence to all 10 quality indicators by patients was associated with better overall (HR: 0.46; 95\% CI: 0.33 to 0.63 ) and progression-free survival (HR: 0.51 ; 95\% CI: 0.39 to 0.67 ). Adherence to either the four treatment indicators, or the six diagnostic indicators by patients was also associated with a significant improvement of survival. In the present study 4-year progression free survival was significantly better in the cohort of patients treated in 2006 to 2008 compared to 2004 to 2005 and 2002 to 2003. Similar results were obtained after data were stratified for T1 tumors only and T2-T4 tumors. Although our survival results can partly be explained by an evolution in the case mix, with considerably more patients with small tumors and negative lymph nodes in more recent years, better adherence to guidelines is likely to be beneficial for the outcome of the patients. In 2010 more than 97\%, 97\% and 95\% of patients had state of the art adjuvant radiotherapeutic, anti-hormonal or cytostatic treatment, respectively, when indicated (according to the Sankt Gallen guidelines), compared to $98 \%, 85 \%$ and $72 \%$ in 2003 . A benchmarking system of the quality of breast cancer care by a nationwide voluntary collaborative network of breast centers in Germany showed similar results [32]. Monitoring pre-defined quality indicators significantly improved preoperative histological confirmation of diagnosis (58\% in 2003 ) to $88 \%$ in 2008 , appropriate endocrine therapy in hormone receptor positive patients (27 to 93\%), appropriate radiotherapy after breast conserving therapy (20 to $79 \%$ ) and appropriate radiotherapy after mastectomy (8 to $65 \%)$.

\section{Conclusions}

EUSOMA has started a voluntary certification process to assess the clinical performance in dedicated European units $[5,18,33]$. So far, 32 breast units in Europe have been recognized to comply with the requirements requested by EUSOMA and other European Union guidelines on the basis of information collected by a questionnaire and by a site visit carried out by an independent team of breast cancer experts. A set of quality indicators was defined by experts from different disciplines based on a literature review. These clearly defined quality parameters, continuous internal audit and external social control by means of a site visit are of paramount importance to optimize adherence to evidence based guidelines and treatment results. The present data shows that data collection results in knowledge which can be used for the benefit of the patients. Clinical pathways for breast cancer have proven to be useful tools to implement better breast cancer care.

\section{Additional file}

Additional file 1: Operable breast cancer.

\section{Abbreviations}

BDCPN: Belgian-Dutch Clinical Pathway Network; EUSOMA: European Society of Breast Cancer Specialists; PCS: Patient Care System.

\section{Competing interests}

None of the authors has any financial of personal relationships with other people or organizations that could inappropriately influences this work.

\section{Authors' contributions}

PD wrote the article and played a major role in developing and auditing the pathway; GV and HVM played a major role in developing the pathway and analyzing the data; AS translated the clinical pathway operable breast cancer from Dutch to English; BT performed the survival analysis; HW was

responsible for part of the data management; LV, JH, PV and LD played a role in developing and auditing the pathway and edited the manuscript. All authors read and approved the final manuscript.

\section{Acknowledgements}

We thank all members of the medical and nursing staff taking care of breast cancer patients in the Sint-Augustinus Hospital, the patients for having confidence in our unit and the hospital directors for stimulating this quality related project.

This paper was presented as an invited lecture at the $8^{\text {th }}$ European Breast cancer Conference, 21-24 March 2012, Vienna.

\section{Author details}

${ }^{1}$ Breast Unit, Department of Gynecology, Sint-Augustinus Hospital, Oosterveldlaan 24, Wilrijk, Belgium. ${ }^{2}$ Medical student, University of Antwerp, Wilrijkstraat 10, 2520, Edegem, Belgium.

Received: 16 December 2012 Accepted: 25 February 2013

Published: 16 March 2013

\section{References}

1. McGlynn EA, Asch SM, Adams J, Keesey J, Hicks J, DeCristofaro A, Kerr A: The quality of health care delivered to adults in the United States. N En/ J Med 2003, 26:2635-2645.

2. Garcia-Etienne CA, Tomatis M, Hell J, Friedrichs K, Kreienberg R, Denk A, Kiechle M, Lorenz-Salehi F, Kimmig R, Emons G, Danael M, Heyls V, Heindrichs U, Rageth CJ, Janni W, Marotti L, Turco MR, Ponti A: Mastectomy trends for early-stage breast cancer: a report from the EUSOMA multiinstitutional European database. Eur J Cancer 2012, 48(13):1947-1956. 
3. Vrijens F, Stordeur S, Beirens K, DeVriese S, Van Eycken E, Vlayen J: Effect of hospital volume on processes of care and 5 year survival after breast cancer: a population based study on 25.000 women. Breast 2012, 21(3):261-266.

4. Asch SM, Kerr EA, Keesey J, Adams JL, Setodji CM, Malik S, McGlynn EA: Who is at greatest risk for receiving poor-quality health care. $N$ Engl J Med 2006, 354:1147-1156.

5. Perry N, Broeders M, de Wolf C, Tornberg S, Holland R, von Karsa L: European guidelines for quality assurance in breast cancer screening and diagnosis. Fourth edition - summary document. Ann Oncol 2008, 19:614-622

6. De Blesser L, Depreitere R, de Wale K, Vanhaecht K, Vlayen J, Sermeus W Defining pathways. J Nurs Manage 2006, 14:553-563.

7. Sermeus W, Vanhaeacht K: What are clinical care pathways? Acta Hosp 2002, 3:5-11.

8. Panella M, Marchisio S, Di Stanislao F: Reducing clinical variations with clinical pathways: do pathways work. Int J Qual Health Care 2003, 15:509-521.

9. De Vries M, van Weert JC, Jansen J, Lemmens VE, Maas HA: Step by step development of clinical care pathways for older cancer patients: necessary or desirable. Eur J Cancer 2007, 43:2170-2178.

10. Smith TJ, Hillner BE: Ensuring quality cancer care by the use of clinical practice guidelines and critical pathways. J Clin Oncol 2001, 19:2886-2897.

11. Senn HJ, Thurliman B, Goldhirsch A, Wood WC, Gelber RD, Coates AS: Comments on the St Gallen Consensus 2003 on the primary therapy of early breast cancer. Breast 2003, 12:569-582.

12. Goldhirsch A, Glick JH, Gelber RD, Coates AS, Thurliman B, Senn HJ: Meeting highlights: international experts consensus of the primary therapy of early breast cancer 2005. Ann Oncol 2005, 16:1569-1583.

13. Harbeck N, Jakesz R: St Gallen 2007: breast cancer treatment consensus report. Breast care 2007, 2:130-134.

14. Goldhirsch A, Ingle JN, Gelber GN, Coates AS, Thurliman B, Senn HJ: Thresholds for therapies: highlight of the St Gallen International experts consensus of the primary therapy of early breast cancer 2009. Ann Oncol 2009, 20:1319-1329.

15. Gnant M, Harbeck N, Thomssen C: St Gallen 2011: summary of consensus discussion. Breast Care 2011, 6(2):136-141.

16. Fitzgibbons PL, Murphy DA, Hammond ET, Allred DC, Valenstein PN: Recommendations for validating estrogen and progesterone receptor immunohistochemistry assays. Arch Pathol Lab Med 2010, 134:930-935.

17. Lopez-Guerrero JA, Navarro S, Noquera R, Almenar S, Pellin A, Vazquez C, Llombart-Bosh A: Histological tumor grade correlates with Her2/c-erbB-2 status in invasive breast cancer: a comparative analysis between immunohistochemical (CB11 clone and Herceptest), FISH and differential PCR procedure. Arkh Patol 2003, 65:50-55

18. Greco M, Marotti L: EUSOMA Executive Committee. Background to EUSOMA guidelines and statement. Eur J Cancer 2006, 42:2200-2204.

19. Blamey RW, Cataliotti L: EUSOMA accreditation of breast units. Eur J Cancer 2006, 42:1331-1337.

20. Van de Mussele H, De Sitter J, Van Looy L: Improving the quality of electronic data registration for clinical pathway at the regional hospital Sint Augustinus Antwerp (Flanders-Belgium): a case study. Stru Health Technol Inform 2006, 122:587-590.

21. Brennan S: Care pathways and electronic patient record: an overview. J Integrated Care Pathways 2001, 5:39-43.

22. SC C, Boldy D: Patients perceived quality of care in hospitals in the context of clinical pathways: development of an approach. J Qual Clin Pract 1999, 19:89-93.

23. Sermeus W, Vanhaecht K: The Belgian-Dutch clinical pathway network. J Integrated Care Pathways 2001, 5:10-14.

24. Kasahara Y, Tawaraya K: Implementation of a clinical pathway for breast cancer - effective tool for variations and changes in treatment methods. Japanse J Breast Cancer 2002, 17:395-401.

25. Santoso U, lau PT, Lim J, Koh CS, Pang Y: The mastectomy clinical pathway: what has it achieved? Ann Acad Med Singapore 2002, 31:440-445.

26. Hwang TG, Wilkins EG, Lowery JC, Gentile J: Implementation and evaluation of a clinical pathway for TRAM breast reconstruction. Plast Reconstr Surg 2000, 105:541-548.

27. Lee BT, Tobias AM, Yueh JH, Bar-Meir ED, Darrah LM, Guglielmi CL, Wood E, Carr JM, Moorman DW: Design and impact of an intraoperative pathway: a new operating room model for team-based practice. J Am Coll Surg 2008, 207:865-873.
28. Ryhanen AM, Rankinen S, Tulus K, Korvenranta H, Leino-Kilpi H: 62 breast cancer patients treatment related knwoledge after clinical pathway in the field of empowerment. Eur J Cancer 2010, 8S:76-77.

29. Geobel RH, Goebel MR: Clinical Pathways can Prevent Malpractice Lawsuits in Breast Cancer and Radiation Therapy, ASCO annual meeting. Abstract No 923. USA: ASCO; 1996.

30. Gemm DH, Wiseman M: Strategic use of clinical pathways. J Oncol Practice 2011, 7:54-56.

31. Cheng SH, Wang J, Lin JL, Horng CF, Lu MC, Ach SM, Hilborne LH, Liu MC, Chen CM, Huang AT: Adherence to quality indicators and survival in patients with breast cancer. Medical Care 2009, 47:217-225.

32. Brucker SY, Schumacher C, Sohn C, Rezai M, Bamberg M, Wallwiener D: Benchmarking the quality of breast cancer care in a nationwide voluntary system: the first five-year results (2003-2007) from Germany as a proof of concept. BMC Cancer 2008, 8:358.

33. Del Turco RM, Ponti A, Bick U, Biganzoli L, Cserni G, Cutuli B, Decker T, Dietel M, Gentilini O, Kuehn T, Mano MP, Mantelinie P, Marotti L, Poortmans P, Rank F, Roe H, Scaffidi E, van der Hage JA, Viale G, Wells C, WelnickaJaskiewicz M, Wengstöm Y, Cataliotti L: Quality indicators in breast cancer care. Eur J Cancer 2010, 46:2344-2356.

doi:10.1186/1477-7819-11-70

Cite this article as: van Dam et al:: A dynamic clinical pathway for the treatment of patients with early breast cancer is a tool for better cancer care: implementation and prospective analysis between 2002-2010. World Journal of Surgical Oncology 2013 11:70

\section{Submit your next manuscript to BioMed Central and take full advantage of:}

- Convenient online submission

- Thorough peer review

- No space constraints or color figure charges

- Immediate publication on acceptance

- Inclusion in PubMed, CAS, Scopus and Google Scholar

- Research which is freely available for redistribution 